\title{
Perspectives on Journal Impact and the Journal of Legal Aspects of Sport
}

\author{
J. O. Spengler, University of Florida
}

\author{
John J. Miller, Troy University
}

The Journal of Legal Aspects of Sport (JLAS) is on solid footing with the number and quality of submissions on the rise. The journal's relationship with Human Kinetics Publishing Company has been a large part of this success. Back issues that were previously inaccessible have been digitized and made available to scholars and practitioners. This means that JLAS should expect growth in the number of citations to its articles and improvement in the citation rate.

Measures of journal quality include those based on a determination of how often a journal is cited among "scientific" journals of similar type (e.g., ISI Journal Citation Reports) or over a broader spectrum of publications (e.g., Harzing's Publish or Perish). A measure of quality for law reviews and legal journals by citation rate also exists (e.g., Washington and Lee School of Law, Law Journals: Submissions and Rankings). Measures of journal quality, however, are sometimes viewed from perspectives beyond citation analysis (Shilbury \& Rentschler, 2007).

Some sport and recreation management departments have an internally developed list of journal rankings in which JLAS is listed as an "A" ranked or top-tier publication. Further, a study by Batista and Pittman (2006) identified JLAS as the most highly ranked sport law journal within the field of sport management. However, common scientific ranking indices, such as ISI Journal Citation Reports, do not currently index JLAS. Given the growth phase of the journal, we believe that this will change, with an ISI Impact Factor listing on the near horizon.

As we thought more deeply about journal quality and $J L A S$, additional issues and questions came to mind. We wondered: What types of JLAS articles (topics) are most often cited by other journals and publications? Does JLAS have an international reach? What fields and disciplines cite $J L A S$ ? Do high quality and high impact journals cite the work of our journal authors? To find answers to these questions, we turned to Harzing's Publish or Perish, a software program that uses Google Scholar and Microsoft Academic Search to obtain and analyze academic citations, and provides certain metrics as well as lists the sources that have cited a publication of interest. Our intent was to use Harzing to gain perspective on the quality of our journal and to satisfy our initial curiosity. A more thorough follow-up would yield additional information. Here is what we discovered.

First, we used Harzing to find the most cited articles and gain a better understanding of article topics that received the most attention in the literature. The 
articles that were cited most often addressed, in no particular order, the following topics: ambush marketing; gender equity and Title IX; right of publicity; ADA and universal access; policy analysis (legislation); managing risk; medical, health, and safety issues; laws and regulations relevant to the NCAA; internships; education and student-athletes; issues in professional and Olympic sport; antitrust; and sport contracts. As one can see, an array of important sports-related aspects have been addressed in JLAS.

Next, we wanted to know whether JLAS articles had been cited in international sources. The results of our search were encouraging. We found JLAS articles that had been cited in journals published in a variety of countries. These included India, China, Australia, France, Canada, the United Kingdom, and Spain. This finding indicates that the journal has some international appeal, and we believe there is the potential for more.

In addition to the international reach of $J L A S$, we wondered about the reach of our journal beyond our specialized field. The answer, after a cursory review of Harzing, was that JLAS has been cited by journals in a variety of fields, including business, law, education/pedagogy, public policy, administration, marketing, health and medicine, and federal law enforcement training. A more thorough review of journal citations would likely reveal more variety. It is encouraging to think about the breadth and scope of the work of JLAS journal authors, and the potential to expand the reach of the journal into additional fields and disciplines.

As another indication of journal quality and reach, we sought to discover the types of high quality journals that have cited $J L A S$. The results of our search are very promising. A sampling of quality journals that have cited JLAS articles include University of Michigan Law Review, Harvard Journal of Sports and Entertainment Law, Harvard Journal of Law and Technology, Boston College Law Review, Cardozo Law Review, Stanford Law \& Policy Review, Ohio State Law Journal, Connecticut Law Review, and Hastings Law Journal. In addition to law reviews, JLAS articles have also been cited in well-respected journals such as Substance Use \& Misuse, Quest, Measurement in Physical Education and Exercise Science, Recreation Sports Journal, Journal of Sport Management, and the American Journal of Preventive Medicine. Further, JLAS articles have informed court decisions and case outcomes, policy decisions and debate on limited liability legislation, health and safety issues, and universal access to sport opportunities.

It is an exciting time for the journal, and we anticipate rapid growth and additional success in the coming years. If you are searching for a journal in which to publish your high quality scholarship, we encourage you to choose the Journal of Legal Aspects of Sport. Your work will have the opportunity to be cited in high impact, quality journals on the domestic or international stage in a variety of disciplines, and in a journal that is highly respected in the parent field. We wish you a happy and productive 2014 and look forward to providing you with quality scholarship from the journal.

\section{References}

Batista, P. J. \& Pittman, A.T. (2006). A descriptive analysis of SRLA members and the study of sport law in academia. Journal of Legal Aspects of Sport, 16, 217-238.

Shilbury, D., \& Rentschler, R. (2007). Assessing sport management journals: A multidimensional examination. Sport Management Review, 10, 31-44. 